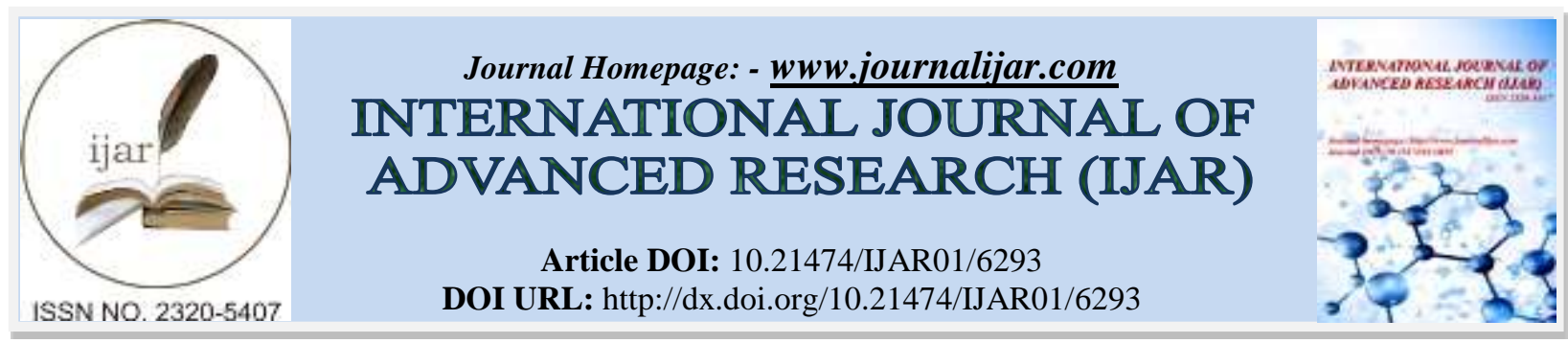

RESEARCH ARTICLE

\title{
ODR AND RESTORATIVE JUSTICE ONLINE: CLARIFYING CONCEPTS DUE TO ITS LEGAL IMPLICATIONS.
}

Oscar Daniel Franco Conforti.

Department of Criminal Law and Department of Restorative Justice, School of Law, University Center of Baja California, Tijuana, Mexico.

Lecturer in Negotiation at the Department of Law and Political Science, Open University of Catalonia, Spain.

\section{Manuscript Info}

\section{Manuscript History}

Received: 12 November 2017

Final Accepted: 14 December 2017

Published: January 2018

Key words:-

Online Dispute Resolution. ODR. Online Dispute Resolution System. ODRS. On-

line Restorative Justice. Information Technology.

\section{Abstract}

One of the fields in which the conflict management is developed is on the Internet where there is no doubt at all it becomes one of the most used tool to resolve conflict, regardless of the nature of the dispute, whether internet related or not. Disputes it is a fact life into the business, whether between buyers and sellers, manufacturers, and suppliers, administrator and governed, etc. But this field it is not the only one, the Online Dispute Resolution has a huge field in different settings. The aim of this article is to review the state of the restorative justice online practices, a further defines some concepts that must be clear when we think what Restorative Justice Online means as one discrete element in the field of ODR, and proposes certain parameters in order to successfully develop this practice in the judicial fields.

Copy Right, IJAR, 2018,. All rights reserved.

\section{Introduction:-}

Restorative Justice is a specialized branch dealing with the criminal and victims of ordinary crimes.

There are three fundamental principles that differentiate this new conception of justice from the traditional one: [1] In the first place, the process, understood as the normalizer of a harmful event in which the needs and emotions emanating from the crime in the victim converge, in the same space, with the made awareness of the damage caused by the victimizer and its personal and social repercussions. [2] Secondly, the presence of all the parties involved, including the community, as indispensable elements for the restorative process. [3] Ultimately, the agreement, which repairs symbolic or materially to the victim, and that allows to reintegrate the offender and restore to the affected community.

Restorative justice has various tools for its practical implementation, criminal mediation, restorative miniprocessescircles or sentencing circles, family and neighborhood conferences,. The choice of one or the other will depend on the needs of the specific case and the different sensitivities of the professionals who lead the process.

The Restorative Justice Process should be developed Online thought the Online Dispute Resolution (ODR) this field was developed by Ethan Katsh in 2001, and it is a filed frequently used for business, in other words, for ecommerce, B2B, consumer, employment, insurance and a wide and varied spectrum of commercial conflicts.

Corresponding Author:- Oscar Daniel Franco Conforti.

Address:- Department of Criminal Law and Department of Restorative Justice, School of Law, 
The advantages of a restorative justice online process are that it permits express emotions such as fear, frustration an find an answer to the question, why me? and at the same time also promote del selt-responsability and awareness of the damage caused, this visualization of both sides should have therapeutic effect but even most importan, it should solve a conflict between parties including the community.

The present research looking for show the potential of the recognition and awareness, the relation between parties it is also regarded as structures is accurately depicted even with their differences and singularities, there is an isomorphism relationship between them and they can crystallize the solution of the dispute if they do so in an associated way, therefore, restorative justice online practice is set to become one of the most an indispensable prevention, re-education, rehabilitation and reintegration screening tool.

\section{How is ODR born?}

To answer this question we have to go back in history and think about the important number of conflicts that began to emerge both locally and internationally with the appearance of buying and selling on the Internet (Rule, 2002), the fact that generated a social phenomenon (I will focus on the legal aspects later on) by the which a buyer is affected in some of their rights when making a purchase on the Internet in a web page and subsequently at the moment to claim their rights, did not found information and consequently know how to do it.

In the European Union the formulas rehearsed at the time of approaching the subject, have been and in a certain way they continue being several, we talk about Online Litigation Resolution (OLR) and Online Dispute Resolution (ODR) according to the differentiation that in the field of Conflict Resolution is made between a Litigation and a Dispute or a Conflict.

The birth certificate to the called Online Dispute Resolution (ODR) was a logical consequence of the fact that the Information Technology (IT) has made available to users different tools in order to solve their disputes.

In this context, the e-mail, an SMS, a conversation in a public or private forum, a chat, a WhatsApp, a videoconference (like Skype ${ }^{\circledR}$ ), etc., can be used to attend and dispense the necessary protection to the buyer against any possible injury to his rights and interests from of the seller.

Fig. 1:- Internet set. IT tools.

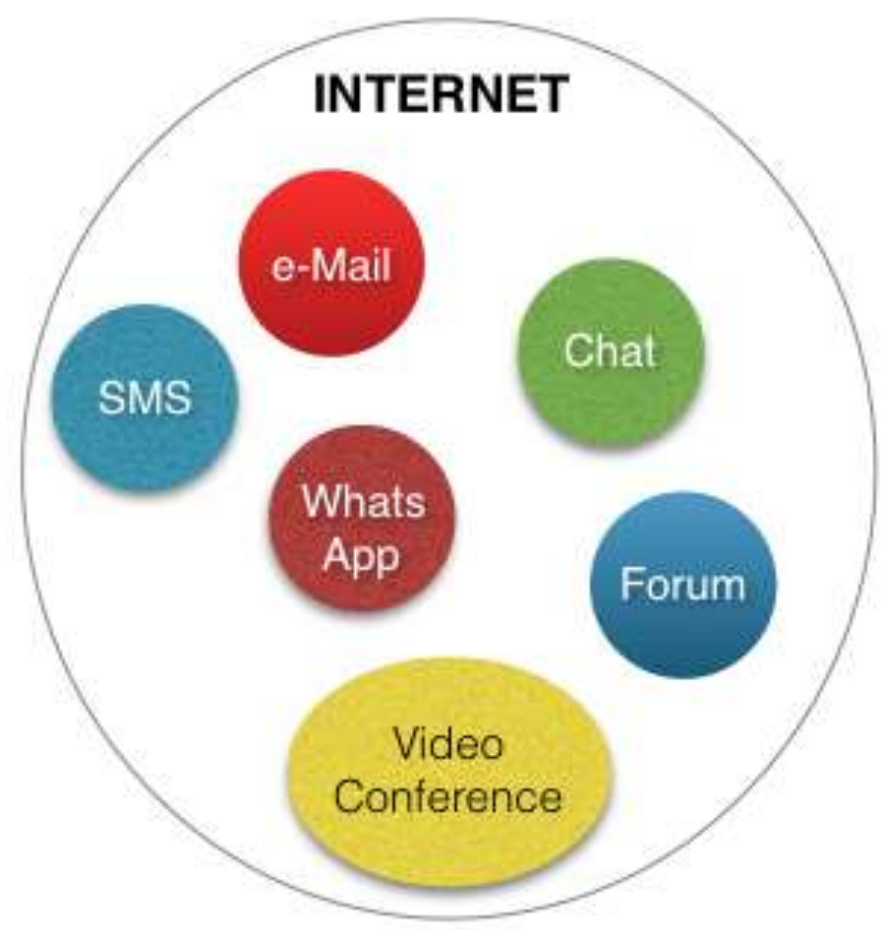

Own Elaboration. 
This being the case, I have to make the first clarification: IT tools are transversal to all methodologies, in other words, there is no correspondence between a tool and a unique method solely. The following graph shows that:

Fig. 2:- Internet set. IT tools transversal to all the Methodologies.

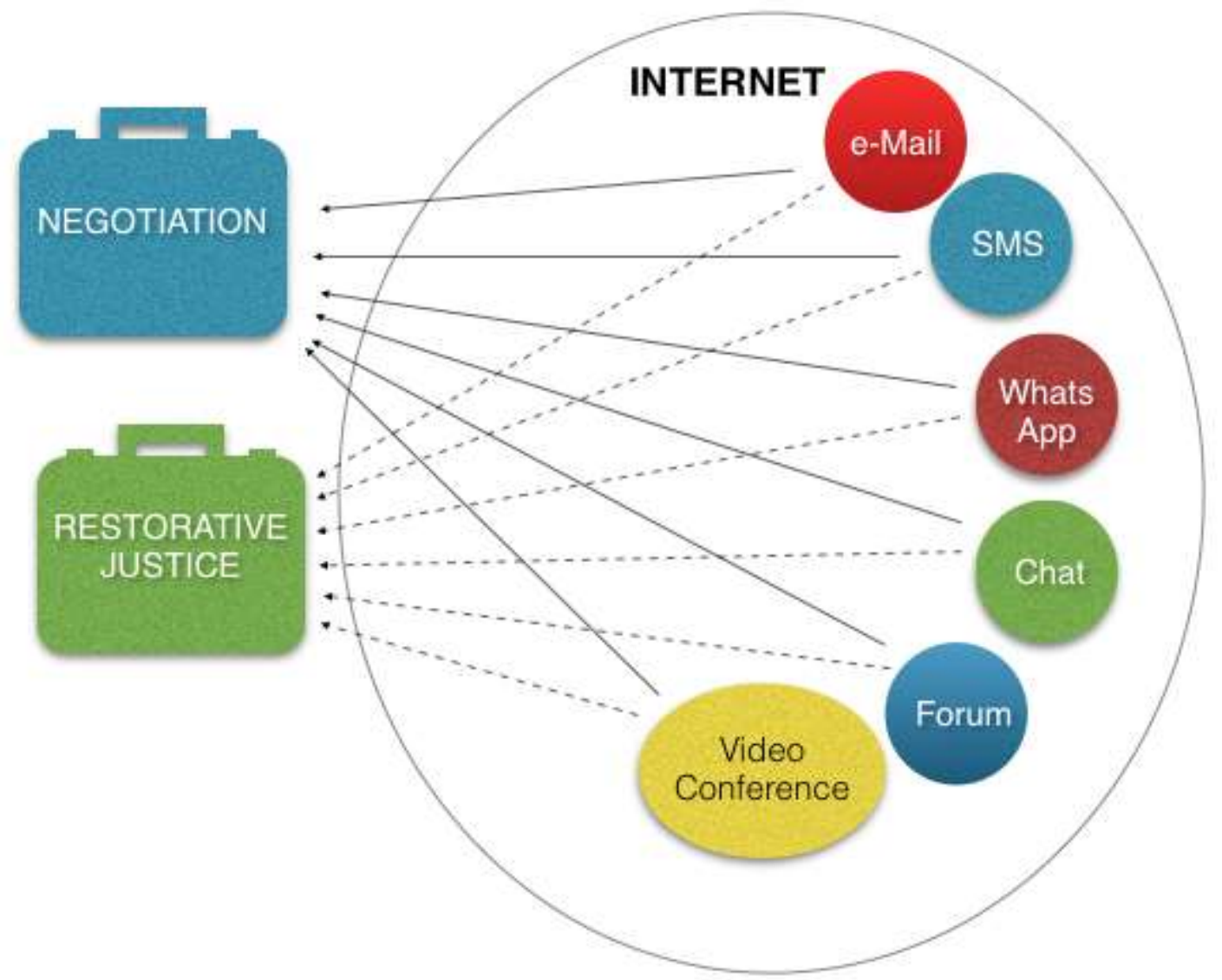

Own Elaboration.

What the graphic aims to make clear is that we should not confuse "IT tools" with "methods of conflict resolution».

Here as the second point, we must clarify that: as the ODR are methodologies through which the parties can solve online a dispute, we should not confuse them with the tools technologies used for this purpose (Conforti, 2013, 2015).

The following graph shows how the traditional ADR methods changes. When the different methodologies of Alternative Dispute Resolution are developing on-line they adjust their denomination to the specific field and incorporate the term Online as a surname; and when they use one or several Internet tools, usually users say that these "become" an ODR because they are used for that purpose, that is, to solve a dispute online, although technically that is not correct because the IT tool will be only a part of the conflict resolution methodology used, I mean, there should be not present a third neutral, and the techniques of the method. 
Fig. 3:- Internet set. IT tools and ODR Methodologies.

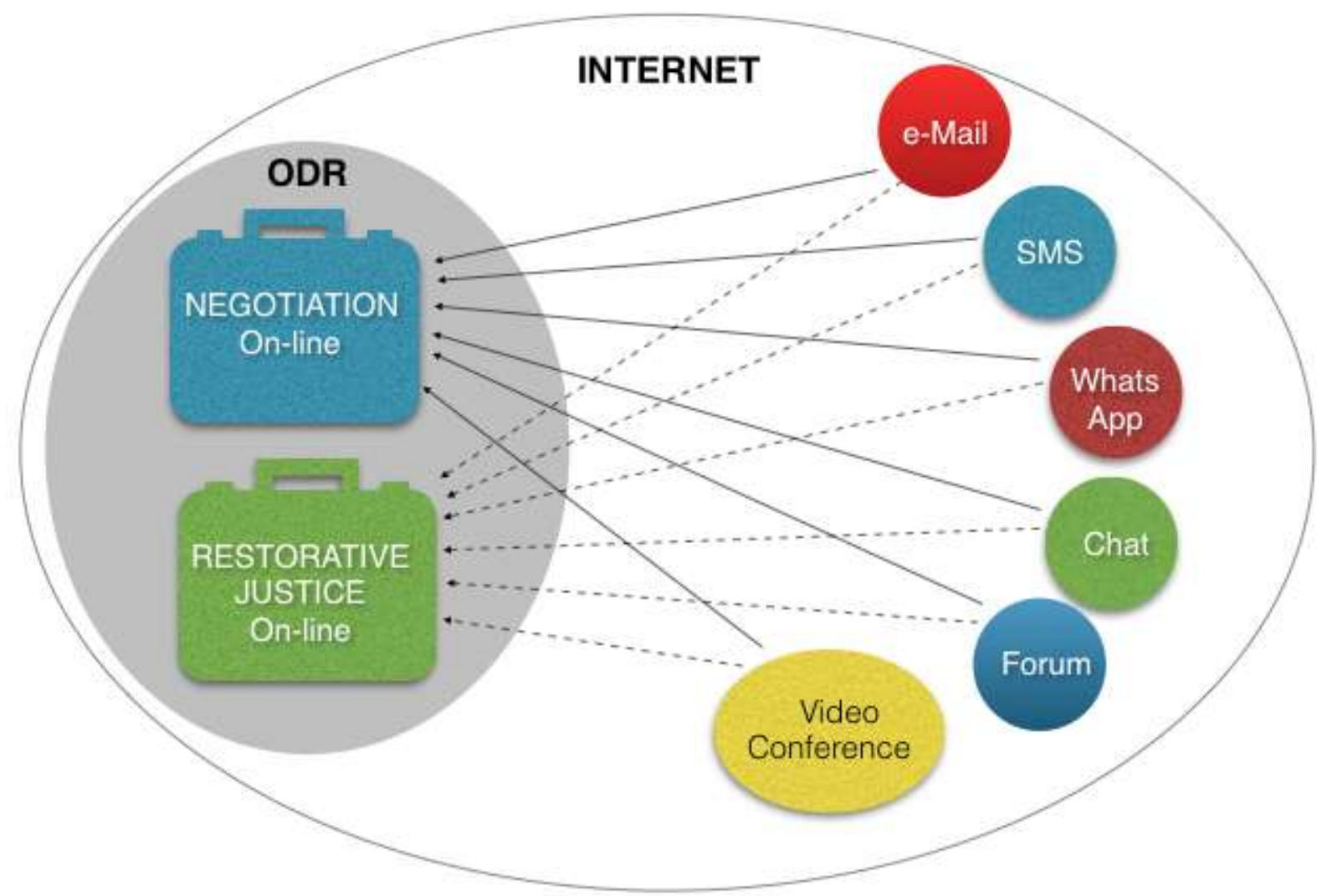

Own Elaboration.

The idea that there are more parts, as a "fifth part", is sufficiently consolidated, this "fifth part" is not another than the technological service provider (Lodder, 2010, p.79), the idea of the fifth part includes all the natural or legal persons who in some way have some degree of participation in the ODR process.

\section{What is the content of the ODR?}

The ODRs are the set (genre) of methodologies through which the parties can solve a dispute through the use of information technology (IT), by this way IT is incorporated as "third" or "fourth part" to the traditional, bi or tripartite, conflict resolution models (Ethan Katsh, 2001).

ODR field is maturating, there is no doubt at all, I say this because this is the second article I am writing on Restorative Justice Online Practice as one of the element in the field.

To continue with the analysis of the ODR process in the next graph I will add all the parties linked to it.. 
Fig. 4:- Internet ser. Provider Services. IT tools. ORDS Provider and ODR Methodologies.

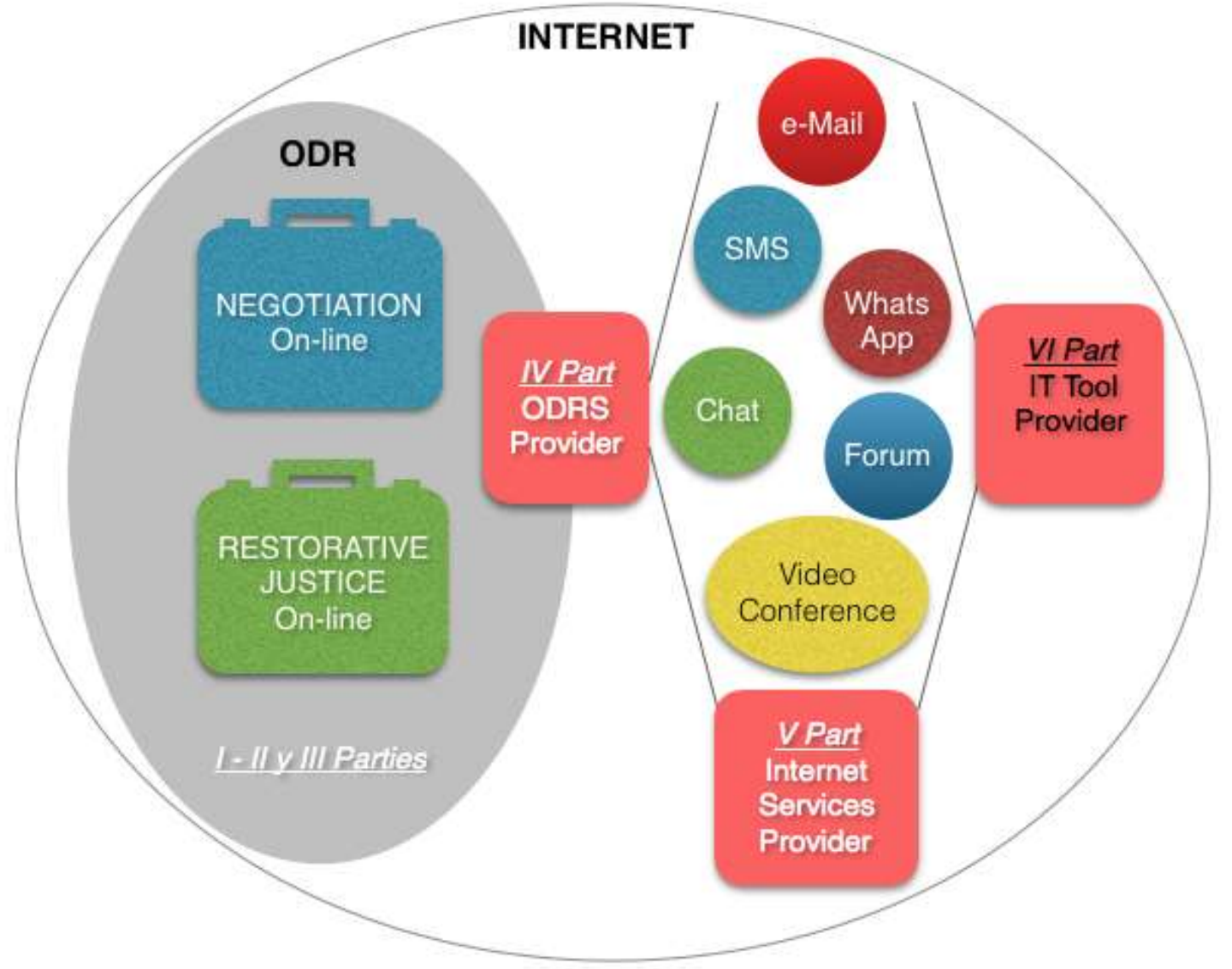

Own Elaboration.

It is clear and quite obvious that the various service providers may be the same legal person but they are not necessarily to be the same one, so I must make the following distinctions here:

1. The ODR set is initially composed by 3 parts (for example, the two parts in conflict and the E-mediator).

2. A fourth part, the provider of the Online Dispute Resolution System, also known by its acronym ORDS, which partially integrates the ODR process (for example, Mediar On Line Platform).

3. The fifth part, the provider of the various information technology tools, singularly considered (for example, WhatsApp Company).

4. Finally a sixth part, which I introduce in accordance of a legal point of view regarding the possible consequences of the hole situation, that means, in one hand the participation level in the process and in the other one the access level to a personal information of the participant with certain legal relevance that could have or acquire this sixth part due to its intervention. I'm talking about the provider of Internet service, hosting, etc., (for example, Movilzone Company).

Nevertheless, we should not forget that the participation of the fifth and sixth part is still so relevant as the technical issues that make the necessary and unavoidable existence of them in the process; from the legal point of view, we must focus on the subject keeping in mind that while the fourth part participates in the ODR process, it is clear that both the fifth and the sixth part, which I just introduced in the scheme, being linked to it, do not participate directly from the ODR process. It follows that the legal consequences for each other should or could necessarily be different and must be specified in future researches.

It is necessary here to focus on the third important clarification: which is that ODR and ODRS are not the same, while in the first case we talk about online methodologies to solve conflicts in the second we talk about a system that uses a certain number of IT tools into a technological platforms. 
Beyond allowing close-up examination of the e-mediation principles (Ebner, 2012) as it is already said, before now and on repeated occasions that we should not confuse Technological tools with Mediation Online (Conforti, 2013, 2014, 2015), this opportunity is to expand the warning to avoid confusion between online methodologies (ODR) and systems or technological platforms (ODRS) because the risk of an error can lead the operator to err in the design of the intervention and with that to take the first step to guarantee the success of the failure.

\section{How do use ODR and Restorative Justice Online?}

While ODR can be used directly by the users, for example with an e-mails exchanging they can solve a dispute; in the same conflict situation it does not happen with Restorative Justice Online, that is to say, that are not exercised directly by the parties, because the figure of the e-facilitator is absolutely necessary to lead the process and ensure the respect to the principles of the restorative justice process, in general, as well as the respect to the particular legal requirements of a restorative justice online practice.

Regarding the restorative justice is it possible to say that, it is an important contemporary expression of timeless standards of justice; while it is true that the On-line Restorative Justice Process should be an ODR (which emphasizes accountability, making amends, and facilitates meetings between victims, offenders, and other persons, such as the community) due to its specificity it is highly recommended to follow the most stringent ODR rules in order to ensure the quality of the process (Conforti, 2017).

A core set of regulatory principles, could be that (Kaufmann-Kohler and Schultz, 2004):

1. The process must be transparent.

2. The identity of parties must be guaranteed.

3. The facilitator must be impartial and independent.

4. The process must be handled swiftly.

5. The system must be amicable with the parties.

6. The process must be neutral and fair for the parties.

Restorative justice practices are intended to repairs the harm caused by ordinary crimes. When victims, offenders, and Community members meet to decide how to do that, the results can be transformational. To achieve the above mentioned objectives, the facilitator will rely on appropriate desktop software to maintain the electronic record of the proceedings, together with a video-conference system that follows 'https` protocols.

As mentioned before "Facilitators need to develop new skills and ethics in his practice online, because they need to be aware that they are working on two levels at the same time: the level of the novel capabilities of the tools employed and the level of the legal consequences of employing this technology.» (Conforti, 2017).

This means that and it is worth as a fourth clarification: not all ODR need secure, private and confidential communications. Secure communications, private and confidential documents will only be indispensable when be required by the parties or the law [for example, this is particularly the case in Spain with the Law 5/2012, of July 6, Mediation in civil and mercantile matters (Spain, 2012), and the Royal Decree 980/2013, of December 13, which develops certain aspects of the Law 5/2012, of July 6, on mediation in civil and commercial matters. BOE, Ministry of Justice, Madrid, Dec. 27 2013a. Section I, n. 310, p. 105296-105311 (Spain, 2013)].

Without prejudice to the previous paragraph, it should be noted that today $90 \%$ of the Internet communications are (or can be) secure, private and confidential because they are encrypted and use secure servers (Https). Proof of this is the fact that WhatsApp has been encrypted very recently. If this were not so, there would be no trade electronic, the $\mathrm{B} 2 \mathrm{~B}$, etc.

I would nevertheless like to say, with regard both the Restorative Justice and Mediation Online, that the most important thing is the guarantee of the identity of the participants in the process (Law 5/2012 art. 24.1) or in other words, "how to avoid identity theft?" (Conforti, 2013: 46) and the answer is that: through the private and secure video-conference (Https) because it is the only technology tool that makes the identity control of the parties feasible and also allows within the restorative practice or mediation process develop the dialogue and creativity as they were described by David Bohm (Bohm, 2013). 
On the basis of the above, you might think it should be sufficient by itself to discourage the idea that ODR are ADR online.

However, this is not the case, that thought is recurrent and unfortunately interestedly fed by both pseudo-specialists and by service providers or ODRS platforms, so it is necessary to continue to pursue and go on reiterating that fifth clarification: ODR are not ADR on the Internet. ADR and ODR are not equivalent (Conforti, 2013: 18).

There are at least three reasons to argue that there is no correspondence at all:

First, because ODR procedures may not necessarily satisfy the "alternative" requirement of ADR, since the ODR form includes the called cybercourts or virtual courts.

Because the technological component of ODR allows the creation of procedures different or non-existent in ADR (Generalitat de Catalunya Departament de Justícia, 2009).

The dialogue and creativity required for an ODR process differ from the ADR processes because in the ODR dialogue is a process of direct and face-to-face meeting that we does not must confuse with endless theorization and speculation (Bohm, 2012) and creativity seeks to avoid self-feeding confusion, raise recognition and awareness that even with their differences and singularities, there is an isomorphism relationship between them and they can crystallize the solution of the dispute if they do so in an associated way (Conforti, 2015).

\section{Where are the ODR, Mediation and Restorative Justice Online legislated?}

Except for consumption, where the recent Law 7/2017, November 2nd, which incorporated into the Spanish legal system the Directive 2013/11/UE is, of the European Parliament and of the Council of 2 May 21st, 2013 on the alternative resolution of consumer litigation (SP / LEG / 22848) (Spain, 2017) regarding ODR there is non specific legislation in Spain. As a general rule, all references are made to the existing legislation in Europe.

In Spain, we have the Law on Mediation in Civil Affairs and Mercantile Law 5/2012, of July 6th (Spain, 2012) and Royal Decree 980/2013, of December 13rd, which develops certain aspects of Law 5/2012, of July 6th, of mediation in civil and commercial matters (Spain, 2013).

\section{Conclusion:-}

It is indispensable to not neglect the design of systems to deal with the disputes and the ordinary crimes consequences that arise and therefore it is advisable to keep in mind the following clarifications:

1. IT tools are transversal to all methodologies, in other words, there is not correspondence between a tool and a single method.

2. The ODR are methodologies through which a dispute can be solved online, we should not confuse them with the technological tools they use for it.

3. ODR and ODRS are not the same, while in the first case we talk about the online methodologies to solve disputes in the second we talk about technological platforms that employ certain IT tools.

4. Not all the ODR need secure, private and confidential communications. The secure, private and confidential communications will only be indispensable when the parties demand it or it is required by law.

5. ODR are not ADRs on the Internet.

6. In future research work, the legal consequences should be addressed as much as posible for the fifth, like the sixth part of the ODR procedure, taking into consideration the degree of participation they have in it.

7. There is no reason to deny the possibility of carrying out an online restorative justice process. The online restorative justice process relies on technology that is easy to use providing necessary privacy and security. 


\section{Bibliography:-}

1. Bohm D. (1987): Unfolding meaning. Routledge. London

2. (2012): About the Dialogue .Kairos. Barcelona. Spain.

3. (2013): About Creativity. Kairos. Barcelona. Spain.

4. Conforti O.D.F. (2013): Pequeño Manual de Mediación Electrónica, 2nd Ed., Acuerdo Justo. Alicante. Spain.

5. (2014a): Electronic Mediation Handbook. Acuerdo Justo. Alicante. Spain.

6. (2014b): "Electronic Mediation of Conflicts in Spain" in Digital Democracy and Governo Eletrônico, Florianópolis, Brazil, n 10, pp. 285-309, 2014.

7. (2015): Online mediation: where we come from, where we are now

8. where are we going. InDret. Magazine for the Analysis of Law, $\mathrm{n}^{\mathbf{0}}$ 4, Procedural Doctrine Section.

9. (2017): From e-Mediation to On-line Restorative Justice in Criminal Law. American Journal of Engineering and Technology Management. Vol. 2, No. 5, 2017, pp. 56-63. doi: 10.11648/j.ajetm.20170205.11

10. Ebner N. (2012): E-mediation in Abdel Wahad M.S., Katsh E. and Rainey D. (Eds.) Online Dispute Resolution: Theory and Practice. A Treatise on Technology and Dispute Resolution. Eleven International Publishing. The Netherlands.

11. Generalitat de Catalunya, Departament de Justícia, Center d’Estudis Jurídics i Formació Specialized. (2009). Materials of the White Paper on Mediation in Catalonia: Pompeu Casanovas, Leonardo Diaz, Juame Magre, Marta Poblet. Marta POBLET, et al . (2009). "ODR and Online Mediation: state of the art and scenarios of use" in Pompeu CASANOVAS et al. (Orgs.). Materials of the White Paper on Mediation in Catalonia: mediation, concepts, scopes, profiles, indicators . Barcelona: Center d'Estudis Jurídics i Formació Especilitzada, 2009. p. 159-169.

12. Katsh E. and Rifkin J. (2001): Online Dispute Resolution: Resolving Conflicts in Cyberspace. Jossey-Bass. San Francisco.

13. Kaufmann-Kohler G. and Schultz T. (2004): Online Dispute Resolution. Challenges for Contemporary Justice. Kluwer Law International. The Nederlands.

14. Lodder, A. R. and Zeleznikow J. (2010): Enhanced Dispute Resolution Through the Use of Information Technology. Cambridge University Press. New York.

15. Rule C. (2002): Online Dispute Resolution for Business. Jossey-Bass, San Francisco, California, USA.

16. SPAIN. Organic Law 10/1995, of November 23, of the Penal Code. BOE, Head of

17. State, Madrid, Nov 24 1995. Section I, n. 281, p. 33987-34058.

18. Or. Organic Law 15/1999, of December 13, on the protection of personal data. BOE,

19. Head of State, Madrid, Dec 14 1999. Section I, n. 298, p. 43088-43099.

20. Law 34/2002, of July 11, on services of the Information Society and electronic commerce BOE, Jefatura del Estado, Madrid, Jul 12 2002. Section I, n. 166, p. 25388-25403.

21. L__ Law 59/2003, of December 19, Electronic signature. BOE, Head of State, Madrid, December 202003. Section I, n. 304, p. 45329-45343.

22. . Law 5/2012, of July 6, on mediation in civil and commercial matters. BOE, Head of State, Madrid, Jul 7 2012a. Section I, n. 162, p. 49224-49242.

23. ___ Royal Decree 980/2013, of December 13, by which certain aspects of Law 5/2012, of July 6, mediation in civil and commercial matters. BOE, Ministry of Justice, Madrid, Dec. 27 2013a. Section I, n. 310, p. 105296105311.

24. L_. Law 7/2017, of November 2, by which it is incorporated into the legal system

25. Spanish Directive 2013/11 / EU, of the European Parliament and of the Council, of 21 May 2013, related to the alternative resolution of consumer litigation. (2017). 